International Journal of Engineering \& Technology, $7(4.20)(2018)$ 146-152
International Journal of Engineering \& Technology
SPC
Website www.sciencepubco.com/index.php/IJET
Research paper

\title{
Influence of Soil Liquefaction on the Structural Performance of Bridges During Earthquakes: Showa Bridge as A Case Study
}

\author{
Mohammed K. Dhahir ${ }^{1 *}$, Wissam Nadir ${ }^{2}$, Mohammed H. Rasool $^{3}$ \\ ${ }^{1}$ College of Water Resources Engineering-Al-Qasim Green University, Babylon, Iraq \\ ${ }^{2}$ College of Water Resources Engineering-Al-Qasim Green University, Babylon, Iraq \\ ${ }^{3}$ College of Water Resources Engineering-Al-Qasim Green University, Babylon, Iraq \\ *Corresponding author E-mail: mohammed.kareem@wrec.uoqasim.edu.iq
}

\begin{abstract}
Liquefaction is generally defined as the loss of contact between soil particles during shaking (earthquakes), and it usually occurs in saturated loose sandy soils where the timescale is insufficient for the water to drain from the pores, thus increasing the excess pore pressure, and thereby floating the sand particles. For regular structures with shallow foundations, liquefaction normally leads to loss of soil strength, which leads to settlement of foundations. On the other hand, bridges are usually supported with piles foundation, which introduces additional effects during liquefaction. Therefore, this paper examines the possible effects of liquefaction on the structural performance of bridges during earthquakes. Furthermore, the failure of Showa Bridge during the 1964 Nagata earthquake was also discussed and analyzed as an example of the catastrophic effects of liquefaction. The analysis shows that the most influential effect during liquefaction is the increase in the unsupported length of piles, which leads to several adverse effects such as increasing the lateral displacement, reduce the buckling capacity, increase the bending moment, and reduce the shaft capacity of the pile. Finally, recommendations regarding the design of pile supported bridges in seismic areas with liquefiable soils have also been suggested.
\end{abstract}

Keywords: Liquefaction; earthquakes; Piles supported bridges; Showa Bridge; collapse.

\section{Introduction}

When subjected to shaking (cyclic loading), a dry loose sandy soil is expected to reduce in volume, as particles are given the energy to move and fill the voids. However, if the voids are filled with water (saturated soil), the timescale, which is in seconds during an earthquake, will be insufficient for the water to drain. As shaking continues, the movement of the sand particles pressurize the fluid within the voids significantly, thus the particles float and lose contact with each other reducing the effective and thereby the lateral stress of soil significantly [1]. Furthermore, and to a lessor extant, liquefaction could also occur in dense sandy soils, while other types of soil are not prone to liquefaction [2].

Liquefaction was reported in many of the major earthquakes during the past century: including the 2011 Christchurch earthquake in New Zealand, the 2001 Arequipa earthquake Peru, the 1989 Loma Prieta earthquake in USA, and the 1964 Niigata earthquake in Japan amongst many others $[3,4,5,6]$. According to many post-earthquake site investigations, liquefaction is considered as one of the main causes of structural failures after major earthquakes. Generally, Liquefaction leads to several effects on the soil; such as loss of strength, settlement, loss of stiffness, boiling, and lateral spreading in sloped areas. Such effects have a catastrophic impact on nearby structures $[7,8,9,10]$.

When designing bridges against earthquake, the seismic actions are normally replaced by a static lateral force, which mainly depends on the stiffness and the mass of the bridge as well as the properties of the underlying soil [11]. Therefore, current codes of practice such as Eurocode 8 [12], Japanese Highway Code of Practice JRA [13], and National Earthquake Hazards Reduction Program Code NEHRP [14] only recommend designing the piles of the bridge against flexures, and thus neglecting all other possible effects of liquefaction on the performance of the pile

A number of recent studies have discussed the possible effect of liquefaction on the seismic behaviour of pile supported bridges such these conducted by Lombardi and Bhattacharya [11], Kimura and Tokimatsu [15] amongst others. However, most of which focused on a certain effect rather than a comprehensive overview that includes solutions. This paper provides a more comprehensive overview of the possible failure mechanisms of pile supported bridges constructed on liquefiable soils during earthquakes and the possible design solutions to address this issue. furthermore, and to illustrate the effect of liquefaction in real life, the failure of Showa bridge Japan during the 1964 Niigata earthquake has been discussed and analyzed.

\section{Collapse of Showa bridge}

To have a better understanding about the possible effects of liquefaction, the failure of Showa bridge Japan during the 1964 Nagata earthquake will be utilized as an example. The case is well documented by many researchers such is Fukuoka [16], Ishihara [17] and Yoshida et al. [18] amongst others. Based on the available literature, a representation of the bridge before failure was drawn as 
shown in Fig.1. The $304 \mathrm{~m}$ long bridge consisted of 12 composite simply supported spans with a constant breadth of $24 \mathrm{~m}$. Except for the side spans, which had a length of about $15 \mathrm{~m}$, all other spans had a length of about $28 \mathrm{~m}$. Each span consists of nine steel girders, each of which is supported by one steel tubular pier at both ends with $610 \mathrm{~mm}$ outside diameter and a variable wall thickness of 16 $9 \mathrm{~mm}$
In 1964, a 7.6 magnitude earthquakes stroke the city of Nagata, Japan. The earthquake led to catastrophic failures in the infrastructure including the Showa bridge, which was located about $55 \mathrm{~km}$ from the epicenter.A photograph of the failure is shown as Fig.2, while a schematic of the failure is illustrated in Fig. 3. Both figures show that piers $P_{5}$ and $P_{6}$ have completely fell into the river. In addition, the movable ends (roller supported ends) of girders between piers $P_{2}-P_{3}$ and $P_{3}-P_{4}$ have dropped into the river, while the fix ends have remained on the top of the piers.
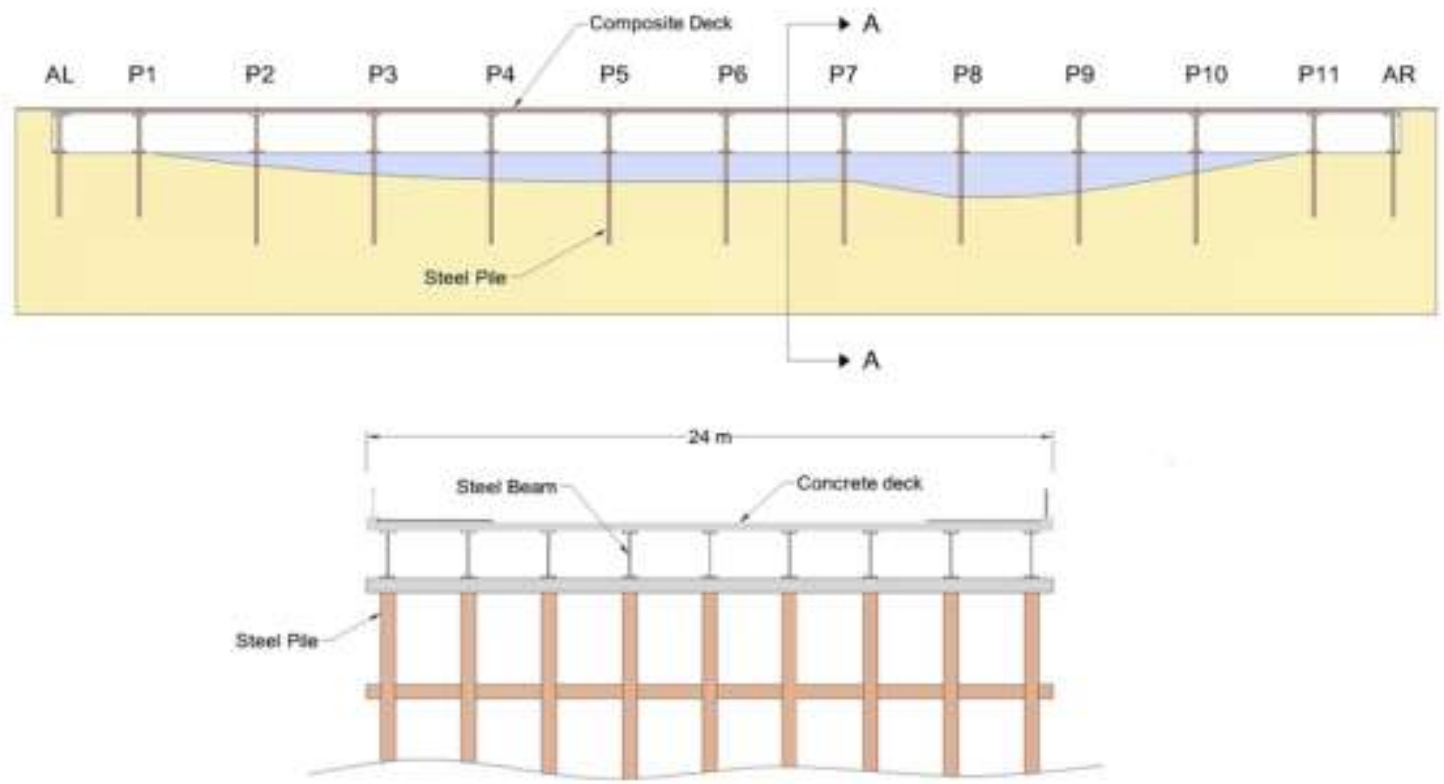

Section A-A

Fig. 1: A representation of Showa Bridge in Japan

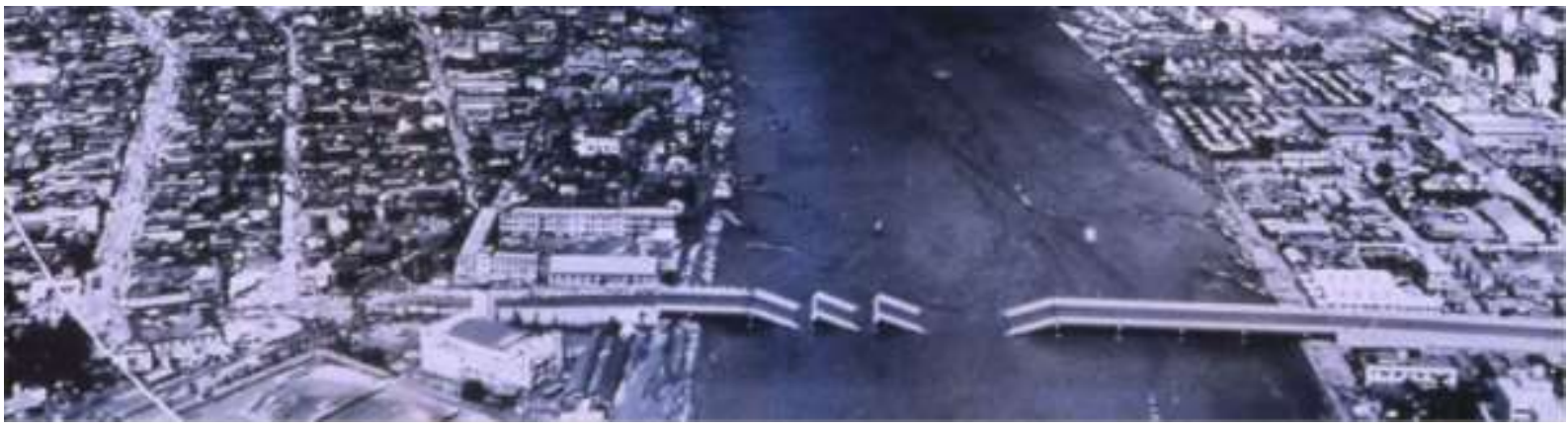

Fig. 2: Collapse of Showa Bridge [16]

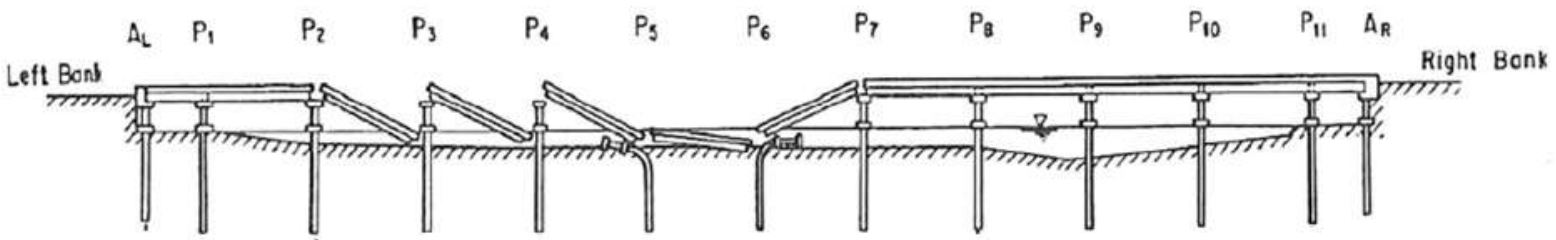

Fig. 3: Diagram of the collapse [21]

Although no consensus has been reached about the cause of the collapse, however, and based on the testimony of a reliable eyewitness, the bridge failed about 1-2 minutes after the earthquake, which rules out the collapse due to the inertia during the shaking of the earthquake $[19,20]$. Furthermore, preliminary site investigations have shown that the loose sandy soil beneath the bridge liquefied up to a depth of $10 \mathrm{~m}$, which is the maximum depth for liquefaction to occur [6], see Fig 4. The figure shows that the liquefaction depth near the left bank was deeper than that near the right bank.

\section{Effect of liquefaction on the structural per- formance of the bridge}

\subsection{Lateral spreading}

As stated earlier, when soil liquefies, the particles float and lose contact with each other. And thus, for grounds with shallow slopes, the soil is expected to flow latterly downslope. In the case of Showa bridge, and given the concave shape of the river bed, reports from 
literature have confirmed that the soil has spread latterly heading towards the center of the river, thus pushing the piles sideway and causing bending stresses. This failure hypothesis has been adopted by a number of researchers such as Fukuoka [16], Hamada and O'Rourke, [22] and Yasuda and Berrill [23] amongst others as the main failure mechanism.

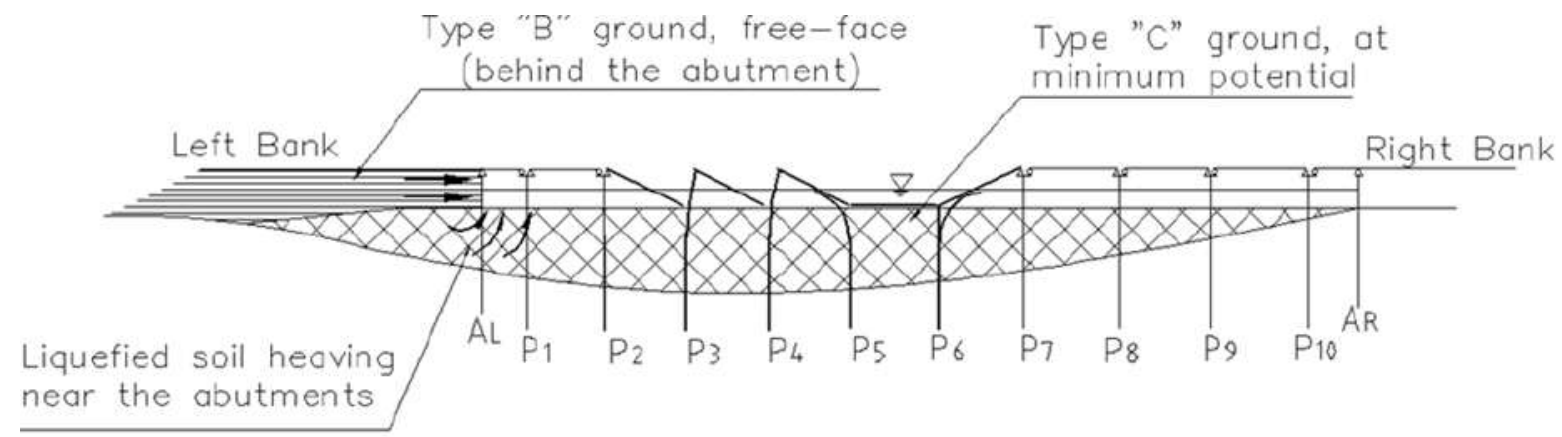

Fig. 4: Liquefaction profile of Showa bridge [6]

However, and since the collapse occurred in piers $\boldsymbol{P}_{\mathbf{5}}$ and $\boldsymbol{P}_{\mathbf{6}}$, which were located near the center of the bridge, where the lateral spreading is minimal, and didn't occur in piers near the abutment particularly $\boldsymbol{P}_{\mathbf{2}}$ and $\boldsymbol{P}_{\mathbf{3}}$, where the lateral spreading is expected to be high. Thus, this hypothesis can be considered as inaccurate, still, it can explain the falling of girders between piers $\boldsymbol{P}_{\mathbf{2}}-\boldsymbol{P}_{\mathbf{3}}$ and $\boldsymbol{P}_{\mathbf{3}}-\boldsymbol{P}_{\mathbf{4}}$ into the river. Fig. 5 shows that the lateral pressure exerted by the soil might have bent the pile sideways, and since the girder is supported by a roller support from one side and restrained against horizontal movement by a hinge from the other side, the movement of the pier may have stripped the girder from its support. According to Fukuoka [16] it only takes a horizontal movement of around 30 $\mathrm{cm}$ to dislodge the girder from its support, see Fig.6. As for piers $\boldsymbol{P}_{\mathbf{5}}$ and $\boldsymbol{P}_{\mathbf{6}}$, a different failure mechanism is proposed later

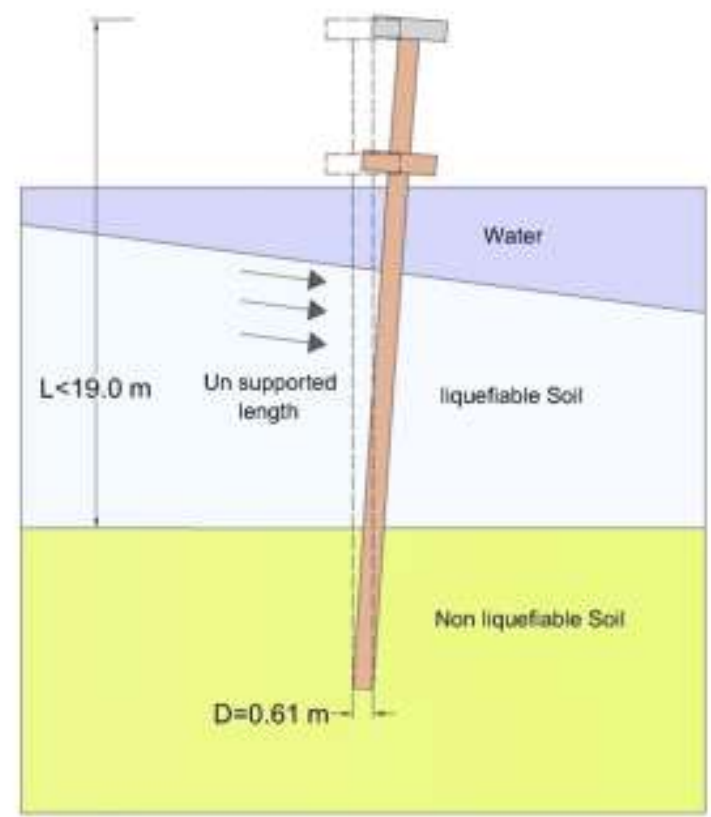

Fig. 5: Effect of lateral spreading during liquefaction.

\subsection{Loss of bearing capacity and settlement}

It is well known that the bearing capacity of piles in sandy soils mainly depends upon the skin friction between the surface of the pile and the surrounding soil, and it can be calculated as follows:

$$
Q_{S}=\tau_{S} \pi D L
$$

Where $\boldsymbol{Q}_{\boldsymbol{S}}$ is the shaft bearing capacity, $\boldsymbol{D}$ is the diameter of the pile, $\boldsymbol{\tau}_{\boldsymbol{S}}$ is the shear friction stress, and it depends on several factors such as the type of pile, the installation method and the type of the surrounding soil. As stated earlier, when soil liquefies, the particles float and lose contact with each other, and thus with the surrounding pile. This leads to decrease the contact length between the soil and the pile $(\boldsymbol{L})$, hence reducing the bearing capacity of the pile significantly. If the applied vertical load exceeds the shaft capacity, the pile is expected to punch the ground and settle down. Generally, in order to avoid end base failure, Bhattacharya et al. [24] recommended that the maximum acceptable settlement should not exceed $10 \%$ of the pile diameter

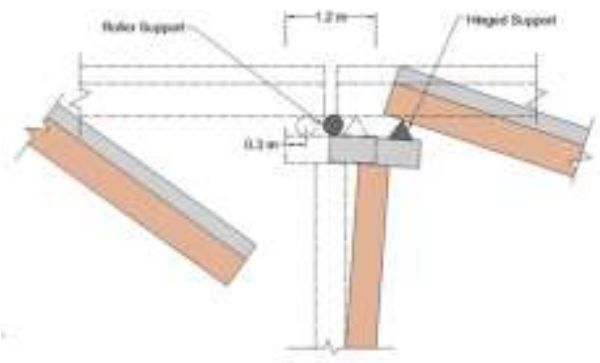

Fig. 6: Possible failure mechanism due to lateral spreading

In case of Showa Bridge, when soil liquefied, the piles immediately lost about 10 to $5 \mathrm{~m}$ of their surface friction. That is around $60 \%$ $30 \%$ of its total capacity, see Fig. 7. As stated earlier, and according to Fukuoka [16], the movable ends (roller supported ends) of girders between piers $\boldsymbol{P}_{\mathbf{2}}-\boldsymbol{P}_{\mathbf{3}}$ and $\boldsymbol{P}_{\mathbf{3}}-\boldsymbol{P}_{\mathbf{4}}$ have dropped into the river, while the fix ends have remained on the top of the piers, see Fig. 3. In order for that to happen, the piers must have either moved to the right or settled down. Therefore, and due the considerable loss of capacity caused by liquefaction, a bearing capacity failure may have occurred, and the piers could have settled down causing the movable ends of the girders to drop into the river, see Fig. 8. Furthermore, and as shown in fig. 4, the depth of liquefaction near the right bank was less than that near the left bank. Thus failure didn't take place in spans near the right bank. However, there is no information within the literature regarding the amount of settlement. Therefore, this theory cannot be confirmed. As for the span between piers $\boldsymbol{P}_{\mathbf{5}}-\boldsymbol{P}_{\mathbf{6}}$ which has completely dropped into the rivers, a different failure mechanism is suggested and it will be discussed next.

\subsection{Loss of buckling capacity}

Normally, slender columns are usually buckled before reaching their ultimate axial load, which is the crushing of the column. According to Euler equation, the buckling capacity of any slender column can be calculated as follows: 


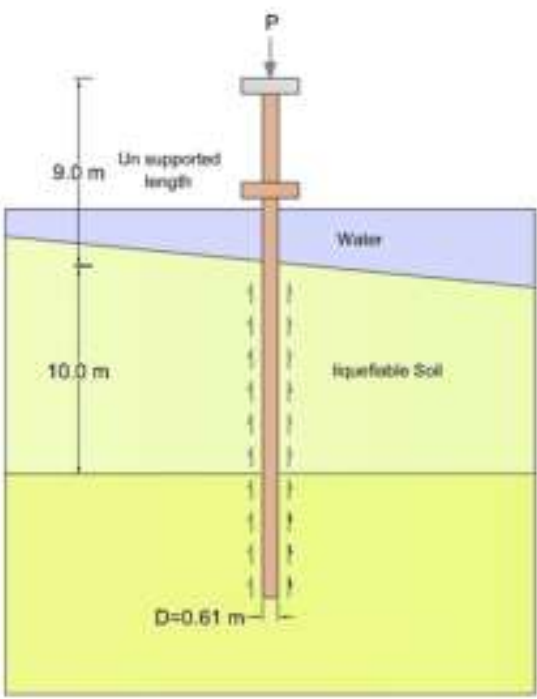

Before Liquefaction

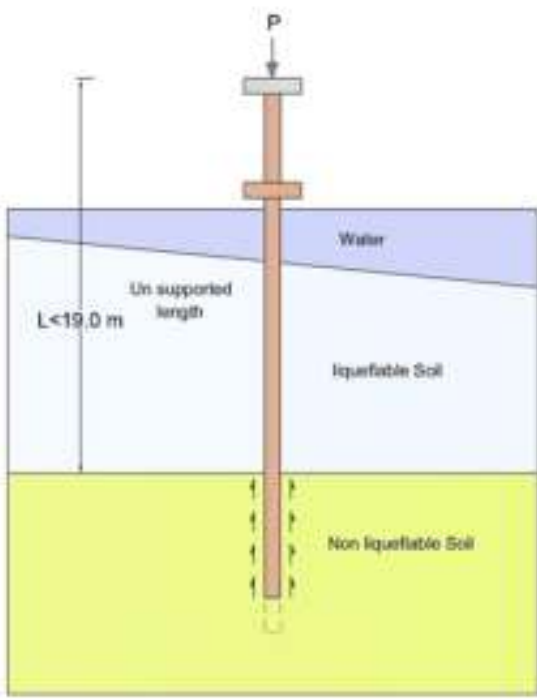

During Liquefaction

Fig. 7. Effect of liquefaction on the shaft capacity of a single pile

$$
P_{c r}=\frac{\pi^{2} E I}{L_{e f f}}
$$

Where $\boldsymbol{P}_{\boldsymbol{c} \boldsymbol{r}}$ is the critical buckling load, $\boldsymbol{E} \& \boldsymbol{I}$ are the modulus of elasticity and the moment of inertia respectively, $\boldsymbol{L}_{\boldsymbol{e f f}}$ is the effective length of the column, and it is a function of the boundary conditions and can be calculated as follows:

$\boldsymbol{L}_{\text {eff }}=\boldsymbol{k l}$

Where $\boldsymbol{l}$ is the actual length of the column, $\boldsymbol{k}$ is a factor that accounts for the boundary conditions.

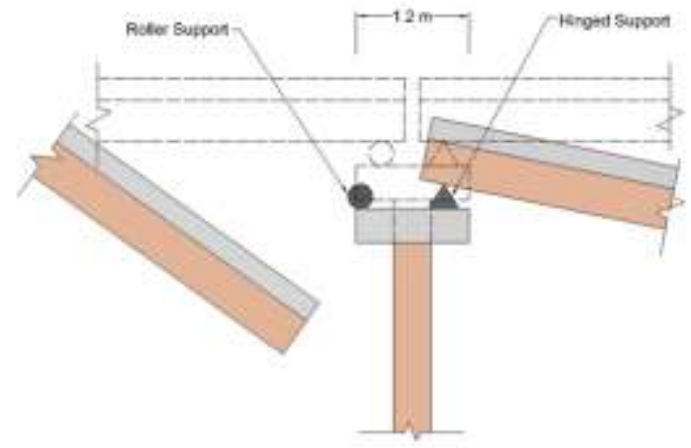

Fig. 8. Proposed failure mechanism of piles near the left bank

Since most of their length is usually embedded within the soil, buckling is not usually considered when designing piles. However, and even before the earthquake, the piles of Showa bridge were susceptible to buckling, giving the fact that they were restrained only from one direction, while left unrestrained for about $9 \mathrm{~m}$ along the longitudinal direction of the bridge, see Fig. 1 and Fig. 9. When liquefaction took place, the piles near the middle of the bridge lost about 10 meters of their lateral support, and thus the unrestrained length became about $19 \mathrm{~m}$. Also, it is important to note that the fixity of piles is not expected to be achieved right at the surface of the ground. Instead, it is known that it can be roughly achieved at a depth of four times the diameter of the pile [25]. Thus, this value must be added to the unsupported length before and during liquefaction, hence it becomes $11.45 \mathrm{~m}$ before liquefaction and $21.45 \mathrm{~m}$ during liquefaction.

Furthermore, and based on the boundary conditions of the pile, which can be considered as fixed at the bottom and free to move at the top, the boundary conditions factor k must be taken as 2 . Due to the increment in the unsupported length and taking into account that the pile's wall thickness varied between $16 \mathrm{~mm}$ at the surface of the ground and 9 at the non-liquefiable soil layer, the pile has lost about $83 \%$ of its buckling capacity, which most likely has led to the collapse of the piles near the center of the bridge. Although, during liquefaction the pile has lost around $60 \%$ of its total capacity, however, and unlike loss of capacity which leads gradually to settlement, buckling failure is sudden and can occur instantaneously. Therefore, it can be concluded that the most likely cause of the collapse of piles $\boldsymbol{P}_{\mathbf{5}}-\boldsymbol{P}_{\mathbf{6}}$ is buckling.

\subsection{Increased natural period}

The natural period is defined as the time required by a structure to complete a full oscillation, and it plays a major role in determining the acceleration imposed on that structure. Fig. 10 illustrates that as the time period decreases, the acceleration increases and vice versa. The acceleration is usually used to determine the amount of lateral force applied on a structure as follows:

$\boldsymbol{F}=\boldsymbol{S}_{\boldsymbol{e}} * \boldsymbol{M}$

Where $\boldsymbol{F}$ is the lateral force applied on a structure due to an earthquake, $\boldsymbol{M}$ is the mass of the structure and $\boldsymbol{S}_{\boldsymbol{e}}$ is the lateral acceleration resulted from shaking during the earthquake. In order to determine the lateral force applied on a bridge during an earthquake, it is usually modeled as a single degree of freedom system as shown in Fig. 11. The natural period of such system depends mainly on the stiffness of the piles and the mass of the bridge, and it can be determined as follows:

$T=\frac{2 \pi}{\sqrt{\frac{3 E I}{M l}}}$

Where $\boldsymbol{T}$ is the natural period, $\boldsymbol{E} \& \boldsymbol{I}$ are the modulus of elasticity and moment of inertia of the pile respectively, $\boldsymbol{M}$ is the mass attached to the pile, $\boldsymbol{l}$ is the unsupported length. 


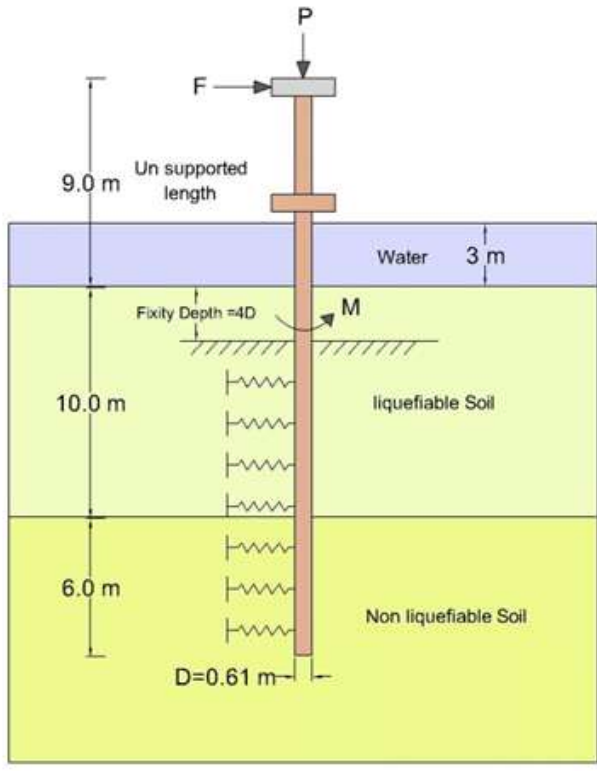

Before Liquefaction

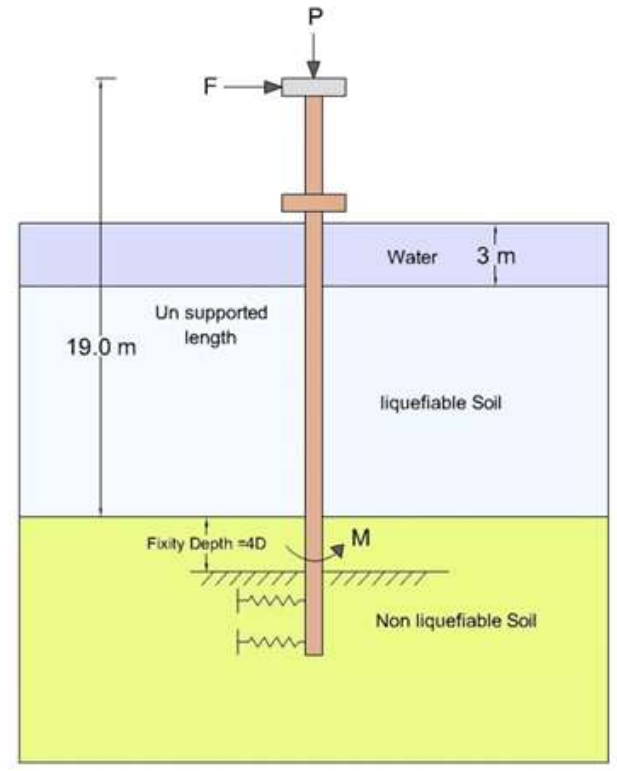

During Liquefaction

Fig. 9. Effect of liquefaction on the effective length of a single pile

In the case of Showa Bridge and due to liquefaction which has increased the unsupported length of the pile as shown in Fig.9, the natural period of the bridge during liquefaction has increased up to about 2.5 times that before liquefaction. However, this increment reduced the acceleration imposed on the bridge drastically, and thus the lateral force induced by the earthquake, see Fig. 10.

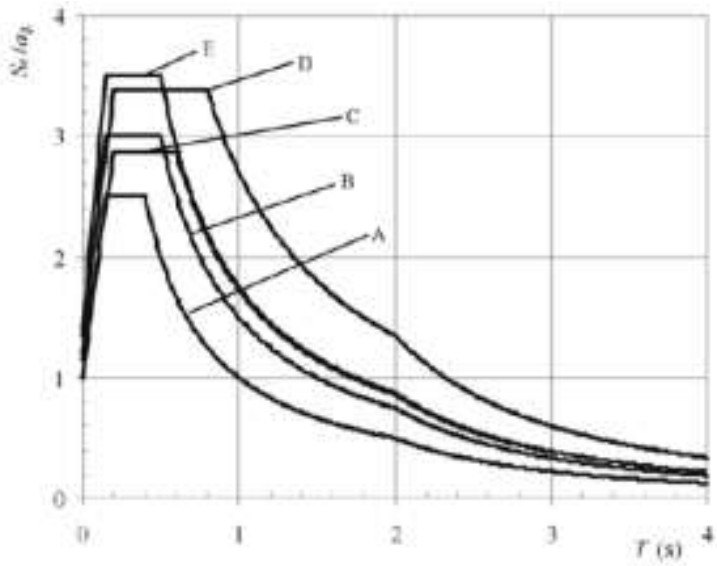

Fig. 10. Elastic response spectra for ground types A to E with 5\% damping [12]

Furthermore, the bending moment applied on the pile due to the lateral force $\left(\boldsymbol{M}_{\boldsymbol{O}}\right)$ can be determined as follows:

$\boldsymbol{M}_{\boldsymbol{o}}=\boldsymbol{F} * \boldsymbol{l}$

Although, the unsupported length of the pile was doubled during liquefaction, which implies that the applied bending moment should have been also doubled, however, as stated earlier the increment in the natural period has decreased the lateral force, and thus, the increment in the unsupported length was cancelled out by the reduction in the lateral force. Therefore, the bending moment imposed by

the lateral force was almost the same before and during liquefaction. That's why the bridge didn't fail during earthquake, since the applied bending moment remained within the design limits.

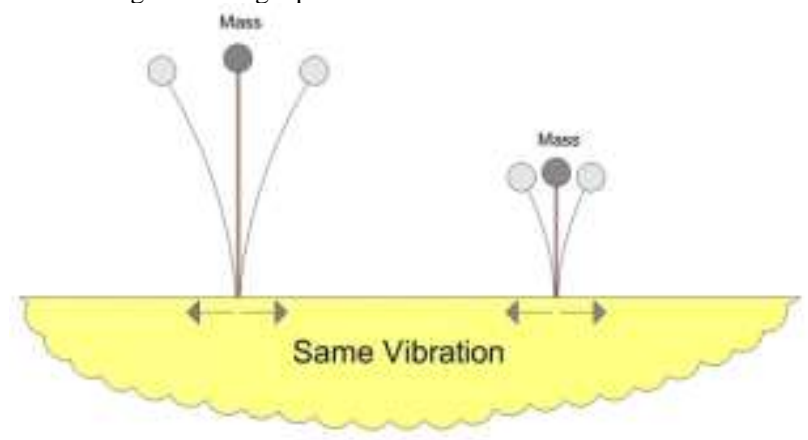

Fig. 11. Effect of the increment in length on the natural frequency and time period

\section{Designing piles in seismic areas with lique- faction hazard}

As illustrated, the most influential effect of liquefaction on pile supported bridges is the increment in the unsupported length of the pile, which leads to several adverse effects such as increasing the lateral displacement, reducing the buckling capacity, increasing the bending moment and reducing the shaft capacity of the pile. On the other hand, current codes of practice such as Eurocode 8 [12], Japanese Highway Code of Practice JRA [13] and National Earthquake Hazards Reduction Program Code NEHRP [14] simply treat piles like beam-column members, and recommends designing piles against the bending moment resulted from the inertia forces and the later spreading of the soil if existed. This approach may result in very large pile sections, and thus complicate the construction process and increase the total cost of construction.

On the other hand and as shown in Fig. 12, connecting the piles using a bracing system (compression members) along both the longitudinal and horizontal directions of the bridge would results in keeping the unsupported length of the pile within acceptable limits, and thus 

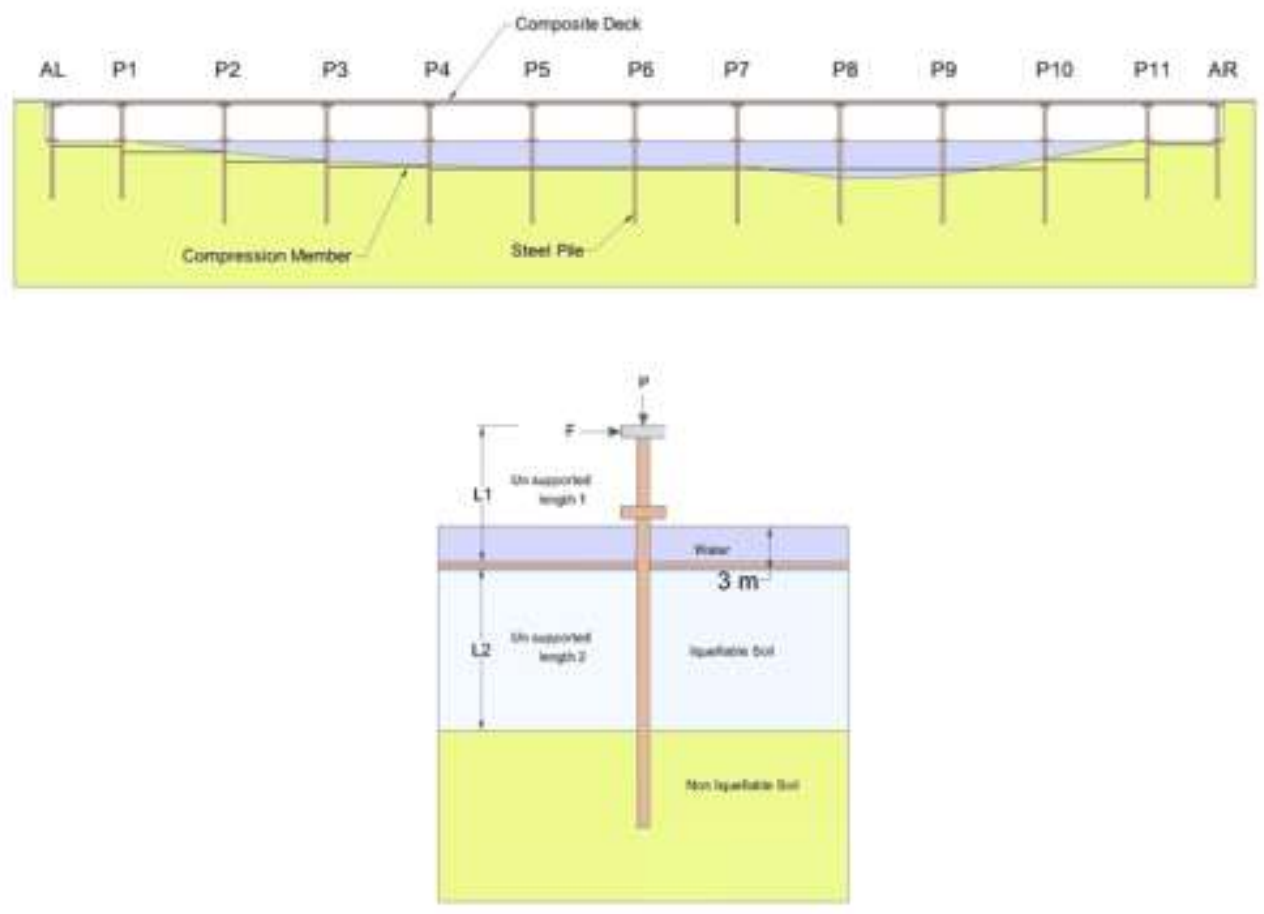

Fig. 12. Suggested bracing system

- $\quad$ Reducing the lateral displacement resulted from lateral spreading

- Preventing the degradation of the piles buckling capacity

- Keeping the applied bending moment resulted from lateral spreading and inertial forces within the limits before liquefaction

Furthermore, it is also important to ensure that the embedded length of the pile in the non-liquefiable layer is providing sufficient shaft capacity to resist the applied axial load. The bracing system must be placed near the bed of the river to prevent blocking the waterway. Also, the system must be designed to be in fixed connection with the piles.

\section{Conclusions}

In this study the possible effects of liquefaction on the structural performance of piles supported bridges during earthquakes was examined. Furthermore, the failure of Showa bridge Japan has been discussed and analyzed as an example of the catastrophic effects of liquefaction. Based on that, the following conclusions are drawn:

- The most influential effect of liquefaction on pile supported bridges is the increment in the unsupported length of the pile, which leads to several adverse effects such as increasing the lateral displacement, reducing the buckling capacity, increasing the bending moment and reducing the shaft capacity of the pile

- The failure of Showa resulted from a combination of lateral spreading and buckling. it is likely that the failure of girders between piers $\mathrm{P} \_2-\mathrm{P} \_3$ and $\mathrm{P} \_3-\mathrm{P} \_4$ was due to the lateral pressure exerted by the soil, which may have bent the pile sideways. And since the girder is supported by a roller support from one side and restrained against horizontal movement by a hinge from the other side, the movement of the pier may have stripped the girder from its support. As for piers P 5-P 6 which completely collapsed, it is more likely that the degradation in buckling capacity resulted from the increment in the unsupported length of the pile during liquefaction was the main cause of failure.

- Connecting the piles using a bracing system (compression members) along both the length of the bridge and its breadth would results in keeping the unsupported length of the pile within acceptable limits, and thus reducing the lateral displacement resulted from lateral spreading, preventing the degradation of the piles buckling capacity and Keeping the applied bending moment resulted from lateral spreading and inertial forces within the limits before liquefaction.

\section{Acknowledgement}

The authors would like to express their special thanks and gratitude to the Higher Committee for Education Development in Iraq (HCED) for their continuous support

\section{Funding body}

This research did not receive any specific grant from funding agencies in the public, commercial, or not-for-profit sectors.

\section{References}

[1] Sasaki, Y., Ohbayashi, J. and Ogata, Y. (2001). "Compressibility of liquefied sand". Proceedings of the Fourth International Confonfrence on Recent Advances in Geotechnical Earthquake Engineering and Soil Dynamics, San Diego, CA, USA. Paper no. 1.62.

[2] Seed, H.B. (1976). "Evaluation of soil liquefaction effects on level ground during earthquakes". Liquefaction problems in geotechnical engineering, ASCE National Convention, Philadelphia, PA, USA. 1104

[3] Haskell, J., Madabhushi, S., Cubrinovski, M., Winkley, A. (2013) "Lateral spreading-induced abutment rotation in the 2011 Christchurch earthquake: observations and analysis". Géotechnique, 63(15), pp.1310-1327. 
[4] Audemard, M., F., Gómez, J., Tavera, H. and Orihuela, G., N. (2005) "Soil liquefaction during the Arequipa Mw 8.4, June 23, 2001 earthquake, southern coastal Peru”. Engineering Geology, 78(3-4), pp.237-255.

[5] Boulanger, R., Mejia, L. and Idriss, I. (1997). "Liquefaction at Moss Landing during Loma Prieta Earthquake". Journal of Geotechnical and Geoenvironmental Engineering, 123(5), pp.453-467.

[6] Hamada, M. (1992). "Large ground deformations and their effects on lifelines: 1964 Niigata earthquake". [Technical report NCEER-920001], New York: US National Center for Earthquake Engineering Research, pp. 1-123.

[7] Lombardi, D. and Bhattacharya, S. (2014). "Liquefaction of soil in the Emilia-Romagna region after the 2012 Northern Italy earthquake sequence". Natural Hazards, 73(3), pp.1749-1770.

[8] Bhattacharya, S., Hyodo, M., Goda, K., Tazoh, T. and Taylor, C. (2011). "Liquefaction of soil in the Tokyo Bay area from the 2011 Tohoku (Japan) earthquake". Soil Dynamics and Earthquake Engineering, 31(11), pp.1618-1628.

[9] Mylonakis, G., Syngros, C., Gazetas, G. and Tazoh, T. (2006). "The role of soil in the collapse of 18 piers of Hanshin Expressway in the Kobe earthquake". Earthquake Engineering \& Structural Dynamics, 35(5), pp.547-575.

[10] Tokimatsu, K. and Asaka, Y. (1998). "Effects of liquefaction induced ground displacements on pile performance in the $1995 \mathrm{Hy}$ ogoken-Nnambu earthquake". Soils And Foundations, 38(Special), pp.163-177.

[11] Lombardi, D. and Bhattacharya, S. (2016). "Evaluation of seismic performance of pile-supported models in liquefiable soils". Earthquake Engineering \& Structural Dynamics, 45(6), pp.1019-1038.

[12] Eurocode 8 (2005).'Design of Structures for Earthquake Resistance Part 5: Foundations, Retaining Structures, Geotechnical Aspects" (English) Comité Européen de Normalisation (CEN), Brussels.

[13] Japanese Road Association (JRA) (2002)." Specification forhighway bridges, Part V, Seismic design" Tokyo, Japan

[14] NEHRP. Commentary (Federal Emergency Management Agency, USA, 369) for seismic regulations for new buildings and other structures; 2000

[15] Kimura, Y. and Tokimatsu, K. (2007). "Buckling stress of slender pile with lateral displacement at the pile head in liquefied soils". Journal of Structural and Construction Engineering (Transactions of AIJ), 72(617), pp.169-175.

[16] Fukuoka, M. (1966). "Damage to civil engineering structures” .Soils and Foundations, 6 (2), pp.45-52.

[17] Ishihara, K. (1993). "Liquefaction and flow failure during earthquakes". Géotechnique, 43(3), pp.351-451.

[18] Yoshida, N., Tazoh, T., Wakamatsu, K., Yasuda S., Towahata I., Nakazawa, H. and Kiku, H. (2007). "Causes of Showa Bridge collapse in the1964 Niigata earthquake based on eye witness testimony". Soils and Foundations, 47(6), pp.1075-1087.

[19] Kawasumi, H. (1968). "General report on the Niigata earthquake 1968, Part3: Highway”. Tokyo, Japan: Tokyo Electrical Engineering College Press, pp.431-50.

[20] Kazama, M., Sento, N., Uzuoka, R., Ishihara, M. (2008). "Progressive damage simulation of foundation pile of the Showa Bridge caused by lateral spreading during 1964 Niigata Earthquake". Geotechnical Engineering for Disaster Mitigation and Rehabilitation $171-176$.

[21] Iwasaki, T. (1986). "Soil liquefaction studies in Japan: State-of-theart". Technical Memorandum No.2239. Tsukuba, Japan: Public Works Research Institute

[22] Hamada M., and O'Rourke T. D. (1992). "Case studies of liquefaction and lifeline performance during past earthquakes - Volume 1: Japanese case studies". Technical Report NCEER-92-0001, National Centre for Earthquake Engineering Research, Buffalo, NY, USA

[23] Yasuda, S. and Berrill, J.B. (2000). "Observations of the earthquake response of foundations in soil profiles containing saturated sands". International Society for Rock Mechanics and Rock Engineering: ISRM International Symposium, Melbourne, Australia

[24] Bhattacharya, S., Bolton, M.D., and Madabhushi, S.P.G. (2005). "A reconsideration of the safety of piled foundations in liquefied soils". Soils and Foundation, 45(4), 13-24

[25] Bhattacharya, S. and Goda, K. (2013). "Probabilistic buckling analysis of axially loaded piles in liquefiable soils". Soil Dynamics and Earthquake Engineering, 45, pp.13-24. 